\title{
Operasyon Odasında Akciğer Koruyucu Mekanik Ventilasyon Stratejileri
}

\section{Lung Protective Mechanic Ventilation Strategies in the Operating Room}

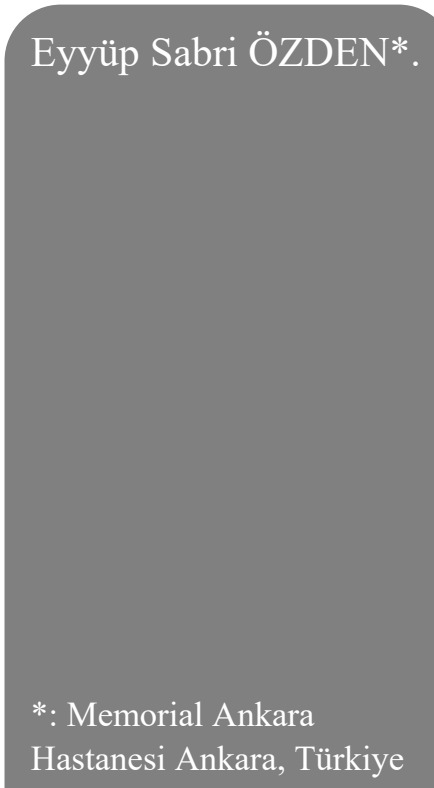

Yazışma Adresi:

Eyyüp Sabri ÖZDEN

dreyupsabri@gmail.com

Elçi Sokak Saray Apt. No:

13/14 Yukarı Ayrancı

Çankaya / ANKARA
Öz

Koruyucu ventilasyon stratejisi, rekruitment manevraları olsun veya olmasın, pozitif ekspirasyon sonu basınç (PEEP) ile düşük Vt'nin (tahmin edilen vücut ağırlığının 4-8 mL / kg aralığında) kullanımını ifade eder. Akut solunum sikıntısı sendromu (ARDS) olan hastalarda koruyucu ventilasyon en uygun uygulama olarak düşünülmüştür. Ancak genel anestezi uygulanan hastalarda sağlıklı akciğerlerin nasıl havalandırılacağına ilişkin az sayıda insan çalışması yapılmıştır.

Anahtar Kelimeler: Koruyucu Ventilasyon Stratejileri, Operasyon Odas1

\begin{abstract}
A protective ventilation strategy refers to the use of low VT (in the range of $4-8 \mathrm{~mL} / \mathrm{kg}$ of the predicted body weight) with positive endexpiratory pressure (PEEP), with or without recruitment manoeuvres. Protective ventilation has been considered the optimal practice in patients suffering from the acute respiratory distress syndrome (ARDS).However, few human studies have assessed how to ventilate healthy lungs in patients undergoing general anaesthesia.
\end{abstract}

Keywords: Protective Ventilation Strategies,Operating Room

\section{Giriş}

Ventilasyon ve oksijenasyon yetersizliği durumlarında, bu duruma neden olan patoloji ortadan kalkıncaya kadar akciğerlerin kollabe olmasını önlemek, ventile edilmesini sağlamak ve kanı yeterince oksijenlemek amacı ile değişik volüm, basınç, akım ve konsantrasyonlardaki hava oksijen karışımlarını ve bu amaçla geliştirilmiş özel aygıtları kullanarak akciğerlerin dışarıdan havalandırılmasına mekanik ventilasyon denilmektedir.

Mekanik ventilasyon ve bu amaçla kullanılan bütün solunum modları; solunum kaslarının, değişik nedenlerle solunum işini normal 
şekilde sürdürmelerinin mümkün olmadığı durumlarda, bozulmanın nedeni ortadan kalkıncaya kadar ventilatuar kasların yaptığı işi üstlenir veya destekler.

Mekanik ventilasyon, genel anestezi sırasında gaz değişimi sağlamak için gerekli destekleyici bir tedavidir ancak yetersiz ventilatör ayarları, ventilasyonun başlangıcında sağlıklı akciğerleri olan hastalarda akciğer hasarını (ALI) başlatabilir ve hatta arttırabilir (1). Yüksek tidal volümle mekanik ventilasyon ameliyathane odalarında yaygın bir uygulamadır çünkü bu strateji sönmüș akciğer dokusunu iyileştirir, ventilasyon-perfüzyon uyumsuzluğunu düzeltir, böylece yüksek inspire edilen oksijen konsantrasyonlarına olan ihtiyaci azaltır (2). Akut respiratuvar distres sendromu (ARDS) olan hastalarda önceki bulguların uyarısı ile, düşük tidal volüm $(\mathrm{Vt})$ ventilasyonu ameliyat odasında giderek daha fazla kullanılmaktadır (3). Bununla birlikte, düşük tidal volüm ventilasyonu, havaya açılmış akciğer alanlarının siklik aşırı gerilmesinden akciğerin korunması için önemli olsa da yeterli değildir ve pozitif ekspirasyon sonu basincin (PEEP) ve rekruitment manevralarının birlikte uygulanması, karın cerrahisi geçiren hastalarda akciğer koruyucu mekanik ventilasyon stratejisinin ayrılmaz bir parçasıdır (4).

Koruyucu ventilasyon stratejisi, rekruitment manevraları olsun veya olmasın, PEEP ile düşük Vt'nin (tahmin edilen vücut ağırlığının 4 $-8 \mathrm{ml} / \mathrm{kg}$ aralığında) kullanımını ifade eder. ARDS olan hastalarda koruyucu ventilasyon en uygun uygulama olarak düşünülmüştür. Ancak genel anestezi uygulanan hastalarda sağlıklı akciğerlerin nasıl havalandırılacağına ilişkin az sayıda insan çalışması yapılmıştır (5).

\section{Düşük Tidal Volümlü Ventilasyon}

1970 ve 1980'li y1llarda yapılan hayvan çalışmaları yüksek tidal volüm ile yapılan mekanik ventilasyonun akciğerlerde hasara yol açabileceğini gösterdi. Yaklaşık 10 yıl önce, ARDS hastalarında basınç hedefli, düşük tidal volümlü mekanik ventilasyon kullanımı ortaya atıldı. 1994 yılındaki mekanik ventilasyon konsensus konferansinin raporunda da bu mekanik ventilasyon yaklaşımını önerildi. Fakat, ARDS Ağının çalışmasına kadar düşük $\mathrm{Vt}$ ile ventilasyon kullanımı birçok grup tarafindan kabul görmedi (6). ARDS A ğ1 çalışmasında, 861 hasta standart Vt $(12 \mathrm{ml} / \mathrm{kg}$, beklenen ağırlık) ve plato basıncı (P plato) (inspirasyon sonunda akımın 0.5 saniye süresin -ce durdurulmasindan sonra) $<50 \mathrm{cmH} 2 \mathrm{O}$ veya düşük Vt (6 ml/kg, beklenen ağırlık) ve P plato $<30 \mathrm{cmH} 2 \mathrm{O}$ olarak randomize edildi (6). Düşük Vt grubunun, 28-günlük mortalitesi standart Vt grubuna göre daha düşük bulundu (\%31'e karş1 \%39.8) (6). Düşük Vt grubunda akciğer haricindeki organ veya sistemlerin bozukluğu olmadan geçirilen gün sayısında anlamlı bir artış görüldü. Her iki grup arasında barotravma açısından bir fark gösterilmedi. $\mathrm{Bu}$ çalışma, ARDS'li hastalarda düşük tidal volümlü, akciğerleri koruyucu mekanik ventilasyonun klinik açıdan önemli olduğunu gösteren en önemli çalışmadır.

ARDS olmayan hastalar arasında yapilan bir meta analizde düşük $\mathrm{Vt}$ ile akciğer koruyucu ventilasyonun atelektazi, pulmoner infeksiyon, mortalite ve akciğer hasarının düşük relatif riskini de içeren daha iyi klinik sonuçlarla ilişkili olduğu bulunmuştur (1).

Son birkaç yıl içinde, hayvan araştırmaları, yüksek Vt ile

ventilasyonun ventilatör ile ilișkili akciğer hasarına (VALI) neden olabileceğini ikna edici bir şekilde göstermiştir. Düşük Vt ile ventilasyon, mortalitenin azalmasina ve ventilatörsüz gün sayısının artmasına neden olmuştur (2).

En yeni klinik veriler alınarak yapılan bir meta 
analiz gösteriyor ki PEEP rekruitment manevrası veya bunların kombinasyonlarının uygulanmasından ziyade düşük tidal volüm kullanımının, intraoperatif mekanik ventilasyon koruyuculuğunun en önemli belirleyici olduğu belirtilmiştir (7). Obez olmayan açık karın cerrahisi geçiren ARDS hastalarına düşük PEEP ile kombine edilmiş düşük Vt (yaklaşık 6 ile $8 \mathrm{ml} / \mathrm{kg}$ ) ile mekanik ventilasyon yapılmalıdır, çünkü rekruitment manevraları ile birlikte yüksek PEEP kullanımı postoperatif pulmoner komplikasyonlara karşı daha fazla koruma sağlamaz ve hemodinamiği bozabilir (7).

\section{PEEP Uygulanması}

PEEP ile yapılan ilk çalışmalar, PEEP'in artışı ile birlikte şantın azaldığını, oksijenasyonun ve akciğer mekaniklerinin düzeldiğini göstermiştir. $\mathrm{Bu}$ düzelmenin ödem sıvısı ile dolu olan alveollerin içindeki sıvının alveollerden interstisyel alana geçişi sebebi ile olduğu düşünülmüştür. Fakat eğer PEEP artış1 sırasında ventilasyon düzeyi aynı düzeyde tutulursa bu akciğerlerin gereğinden fazla gerilmesine (indirekt olarak hava basıncının artıșına) sebep olabilir ve PEEP yararlı olan etkilerini ortadan kaldırabilir ve hatta durumu daha da kötüleştirebilir .

ARDS Ağının çalışması mortalite faydası göstermesine rağmen, daha önceki bir kaç çalışma bunun aksine sonuçlar bildirmişti. ARDS Ağınin çalışmasından sonra yapıIan bir başka çalışma bunun alveollerdeki derekruitmenta bağlı olabileceğini ileri sürdü. Richard ve arkadaşlarının çalışması değişik PEEP düzeylerinde bakıldığında rekruit edilen volüm ve oksijenasyonun düşük $\mathrm{Vt}$ kullanıldığında daha düşük olduğunu gösterdi (8). Fakat eğer PEEP alt infleksiyon noktasının üzerine çıkarılırsa (4 cmH2O artış ile) veya 45 saniye boyunca süren inflasyonlar uygulanırsa rekruit edilen volumün tekrar kazanıldığ1 gösterildi. Bu çalışma, periyodik uzun süreli inflasyonlar (sigh) veya PEEP'teki artışların gerekli olabileceğini fikrini öne sürdü. ARDS Ağ1 çalışmasında, düşük Vt 'li grup diğer gruba oranla daha yüksek PEEP düzeyi göstermekteydi (9 vs. 8 cmH2O) (6). Fakat asidozu önlemek amaciyla solunum sayısının arttırılması düșük Vt'li grupta oto-PEEP gelişmesi sebebi ile total PEEP'in olduğundan daha da yüksek olmasına neden olmuştur.

ARDS Ağı çalışma grubunu bu ilk çalışmasını takip eden çalışmasında PEEP düzeyinin düşük Vt'li ventilasyona etkisi araştırıldı (9). 549 hastadan sonra çalışma durduruldu. Hem düşük (ortalama $8.3 \mathrm{cmH} 2 \mathrm{O}$ ) hem de yuksek (ortalama

$13.2 \mathrm{cmH2O}$ ) PEEP grubunda mortalite düşük bulundu ve ventilasyon parametrelerinin ayarlanmasının ARDS'nin mortalitesine etkili olabileceğini doğruladı. Fakat yüksek PEEP grubunda olan hastaların daha hasta olduğu ve bu sebeple ölüm riskinin daha yüksek olduğu unutulmamalıdır. Pnömoperitonyum sırasında koruyucu akciğer ventilasyonu (PEEP ile düşük $\mathrm{Vt}$ ), laparoskopik hepatobiliyer ameliyattan sonra alveolar rekruitment manevras1 uygulanmasi konvansiyonel ventilasyondan daha az pulmoner komplikasyon insidansı ile ilişkilendirildi (10).

PROVHILO çalışması, yüksek PEEP ile düşük PEEP arasinda postoperatif pulmoner komplikasyonlarda fark olmadığını, oysa IMPROVE çalışmasında düşük PEEP, yüksek $\mathrm{Vt}$ grubunda postoperatif pulmoner komplikasyonların daha fazla olduğu görüldü (11).

Domuzlarda yapılan bir çalışmada randomize olarak 3 gruba ayrilan hayvanlar $15 \mathrm{ml} / \mathrm{kg} \mathrm{Vt}$ tahmin edilen vücut ağırlığ $1+3 \mathrm{cmH} 2 \mathrm{O}$ PEEP $(\mathrm{H}-\mathrm{Vt} / 3)$ ve $6 \mathrm{ml} / \mathrm{kg} \mathrm{Vt}$ tahmin edilen vücut ağırlığ $+3 \mathrm{cmH} 2 \mathrm{O}$ PEEP (L-Vt / 3) 
gruplariyla,

$6 \mathrm{ml} / \mathrm{kg} \mathrm{Vt}$ tahmin edilen vücut ağırlığ $1+10$ cmH2O PEEP (L-Vt / 10) grubu karşılaştırıldı. L-Vt / 10 grubunda bronkoalveolar lavaj (BAL) 'da inflamatuar mediatörlerde 6 kat artış gösterildi. BAL'daki sitokinler, H-Vt / 3 ve LVt / 3 gruplarında benzerdi. Grup H-Vt / 3'ün diğer gruplara göre akciğer hasar puanı belirgin şekilde düşüktü. İntraoperatif stratejileri karşılaştırıldığında, yüksek PEEP ile ventilasyon, inflamatuvar belirteçlerin üretimini arttırdığı, düşük PEEP' in, inflamatuar belirteçlerin seviyelerini düşürmüş olduğu tespit edildi. Yüksek Vt / düşük PEEP, histolojik olarak daha az akciğer hasarına yol açtığ1 gösterilmiştir (12).

\section{Alveollerin \\ Tekrar (Rekruitment) \\ Kazanılması}

Optimal gaz değişimi ve oksijenasyon için akciğerlerin "açık" olması gereklidir. Aynı zamanda, hava yolu basınçları en düşük düzeyde olmalı ki, hemodinamik yan etkileri en aza indirgenmeli. "Açık" akciğer ventilasyonu akciğerin normal, hastalıksızken olan halini çağrıştırır. Açı akciğer ventilasyonu, ARDS'nin en önemli bulgusu olan hipoksemi, akciğer içi șant ve atelektazi yaratabilen, infeksiyon riskini arttıran ve ölüme götürebilen kapalı akciğer alanlarının tekrar açılması ve kapanmasının önlenmesi konseptine dayanmaktadır.

Kapalı olan alveolun tekrar kazanılması için yüksek basınca ihtiyaç varken, açılan akciğer alanlarının kapanmasını

önlemek için gerekli basınç daha azdır. Kritik açılma basıncına ulaşıldığında kapalı olan akciğer açılabilir. Alveol içindeki basınç belli bir basıncın altına düşmediği müddetçe alveol açık kalır, fakat eğer düşerse kapanır ve tekrar açılabilmesi için yine yüksek basınca ihtiyaç duyulur. "Açık" akciğer ventilasyonu bir strateji olarak kullanılırken, inspiratuar basınc1 arttırmanın ilk amacı kapalı olan alveolleri tekrar kazanabilmek ve kritik açılma basıncını öğrenebilmektir. Crotti ve arkadaşları "açık akciğer ventilasyonu" sağlayarak yaptıkları çalışmada, ARDS'li beş hastada çeşitli inspiratuar $\mathrm{P}$ plato $(10-45 \mathrm{cmH} 2 \mathrm{O})$ ve PEEP düzeyleri (5-20 $\mathrm{cmH} 2 \mathrm{O})$ uyguladılar. Akciğer rekruitment manevrasının, bütün inspirasyon süresince olduğunu (alt veya üst infleksiyon noktalanndan bağımsız olarak) ve akciğerleri bağımsız (üstte kalan) bölümlerinden başlayıp bağımlı (altta kalan) bölümlerine doğru ilerlediğini gösterdiler (13).

\section{Yüzüstü çevirme (Prone pozisyonu)}

Diğer bir akciğerleri koruyucu ve oksijenasyonu düzeltici strateji de ARDS hastalarının sirt üstü pozisyondan yüzüstü pozisyona çevrilmesidir. $\mathrm{Bu}$ strateji ile oksijenasyonun düzelme mekanizmasının daha önce bağımlı (altta kalan) bölümlerde ventilasyonun düzeltilmesi olduğu hipotez edilmiştir.Avrupa prone-supine çalışma grubunun bu konuda randomize, kontrollü ve altı ay takipli bir çalışmasında 152 hasta günde altı saatten fazla süre ile 10 gün boyunca yüz üstü, diğer 152 hasta da sirt üstü pozisyonda tutuldu. Yüz üstü grubundaki hastalarda oksijenasyon düzelmesine rağmen, 10 günlük mortalite hızında iki grup arasında bir fark bulunamadı (\%21 vs \%25). Benzer bir şekilde yoğun bakımdan çıkış anındaki ve altı aylık mortalite de bir fark bulunamad1 (14).

\section{Klinik Uygulama}

Akciğerleri koruyucu mekanik ventilasyon için tavsiye edilebilecek ilk ventilatör parametreleri Vt $5-7 \mathrm{ml} / \mathrm{kg}$, solunum sayıs $=20-30 / \mathrm{dk}$, $\mathrm{PEEP}=10-12 \mathrm{cmH} 2 \mathrm{O}$ ve $\mathrm{FiO} 2$

1.0. İlk parametreler uygulandiktan sonra (hemodinamik resusitasyon yapılmak şartı ile), 
ventilatör parametreleri, PEEP ayarlanarak P / F oranı 200 üzerine çıkartılmaya çalışılır. Bu arada $\mathrm{Vt}^{6}$ de, eğer $\mathrm{P}$ plato $30 \mathrm{cmH} 2 \mathrm{O}$ üzerinde ise azaltılır. Amaç, yeterli oksijenasyon için FiO2 0.6 altında ve $\mathrm{P}$ plato $30 \mathrm{cmH} 2 \mathrm{O}$ altında tutmaktır. Eğer hasta hemodinamik olarak normal ise, rekruitment manevraları kullanılarak, alveoller tekrar kazanılmaya çalışılabilir.

Buraya kadar anlatmış olduğumuz uygulama daha çok yoğun bakım hastalarında kullanılmaktadır. Ancak anestezi ile yoğun bakım hastalarında uygulanan yöntemlerle ilgili çalışmalarda aralarında anlamlı bir fark olmadığ1 gösterilmiştir. Major torakal ve abdominal cerrahide düşük tidal volümle fonksiyonel rezidüel kapasite (FRK) kaybını azaltmak mümkündür.Atelektaziden korunmada perioperatif akciğer koruyucu yaklaşımla anestezi induksiyonu sırasında devamlı havayolu basıncı (CPAP), entübasyon sonrası PEEP ve kontrollü mekanik ventilasyon (CMV) kullanımı, intraoperatif akciğer rekruitment manevralar1, Vt $4-5 \mathrm{ml} / \mathrm{kg}$ ve $\mathrm{P}$ plato $20 \mathrm{cmH} 2 \mathrm{O}$ altında olacak şekilde düşük oksiijen fraksiyonu verilişi ve postoperatif noninvaziv ventilasyon desteği ile erken mobilizasyon, derin solunum egzersizleri atelektotravma ve volutravma riskini azaltarak multiorgan yetmezliği (MODS) gelişimini engelleyebileceği ileri sürülmektedir (15).

Düşük Vt kullanımı mekanik ventilatörün hemodinamik toleransını geliştirir. Bunların ötesinde sıvı ihtiyacındaki azalmaya bağlı bu yararlı hemodinamik etkiler sekonder ALI/ ARDS insidansının azalmasına katkıda bulunur (11). Pnömonektomili 170 hastanın intraoperatif $\mathrm{Vt}$ verileri toplanmış. \%18 hastada postoperatif solunum yetmezliği geliștiği bunların yarısında da ALI/ARDS gelişmiştir. Postoperatif solunum yetmezliği gelişmesinde risk faktörlerinin intraoperatif yüksek Vt ve sıv1 verilmesi olduğu belirtilmiştir (16).
Özefagus cerrahisi planlanan 52 hasta 2 gruba ayrilarak, konvansiyonel strateji (Vt $9 \mathrm{ml} / \mathrm{kg}$ PEEP $\varnothing$ ) ve koruyucu ventilasyon (2 akciğer ventilasyonunda $\mathrm{Vt} 9 \mathrm{ml} / \mathrm{kg}$, tek akc ventilasyonunda $\mathrm{Vt} \quad 5 \mathrm{ml} / \mathrm{kg}$ operasyon süresince

5 cmH2O PEEP) uygulanmış. Koruyucu ventilasyon uygulanan hastalarda ameliyat sonrası 1 saat ve tek akciğer ventilasyonu süresince arteriyel oksijenasyon / FiO2 oranında artış ve postoperatif MV süresinde azalma olduğu gözlenmiş. Operasyondan 18 saat sonra tek akciğer ventilasyonunda kandaki IL-1, IL-6 ve IL-8 düzeylerinde azalma olduğu tespit edilmiş (17).

Obez olmayan hastalarda da obez hastalar gibi induksiyon sırasında PEEP kullanımı ile atelektazi önlenmiş olur (18). Açık bariatrik cerrahi geçiren morbid obez hastalarda $15 \mathrm{sn}$ $40 \mathrm{cmH} 2 \mathrm{O}$ pozitif inspiratuar basınçla rekruitment manevras $1+8 \mathrm{cmH} 2 \mathrm{O}$ PEEP uygulanımı intraarteryel oksijenasyonu artırır (19).

Laparoskopik bariatrik cerrahi geçiren morbid obez hastalarda alveolar rekruitment manevras1 (PIP $50 \mathrm{cmH} 2 \mathrm{O}$ - 4 destek) + PEEP $12 \mathrm{cmH} 2 \mathrm{O}$ solunum sisteminin dinamik kompliyansını ve intraoperatif $\mathrm{PaO} 2$ artırır. Fakat hastalar daha fazla vazopresör ihtiyacı duyar, ekstübasyon sonrasinda bu etkiler kaybolur (18).

Akciğerleri koruyucu mekanik ventilasyonda temel hedef bölgesel inspirasyon sonu gerilimi minimuma indirmek, alveolar inflamasyonla birlikte alveolar hasarı azaltmaktır.

Normal akciğerli düşük riskli cerrahi geçiren birçok hastada kısa süreli $\mathrm{MV}$ ' da Vt $10 \mathrm{ml} / \mathrm{kg}$ iken inspirasyon sonu gerilimi düşüktür. Düşük Plato basinc1 ve spontan solumuyorsa düşük Vt endike değildir. P plato artarsa VT' de $\sim 6 \mathrm{ml} / \mathrm{kg}$ düşürülmelidir. PEEP az yada hiç kullanılmadıysa atelektazi gelişebilir. Yeterli 
PEEP atelektaziyi minimalize etmek ve oksijenasyonu sağlamak için kullanılmalıdır.

Koruyucu ventilasyon (düşük Vt (6-8ml / kg tahmin edilen vücut ağırlığı) + PEEP + rekruitment manevrasi) ile konvansiyonel ventilasyon $(\mathrm{Vt} \geq 9 \mathrm{ml} / \mathrm{kg}$ tahmin edilen vücut ağırlığg) karşılaştırıldığında postoperatif akciğer enfeksiyonu, atelektazi, ALI ve hastanede kalış süresi insidasında istatistiksel olarak anlamlı bir azalma görüldü. $\mathrm{Bu}$ çalıșmaların meta analizi düşük tidal volümün, konvansiyonel ventilasyon stratejisi ile karşılaştırıldığında postoperatif akciğer enfeksiyonu insidansında anlamlı azalma olduğunu gösterdi. (20)

Son çıkan veriler, daha düşük tidal volüm (6$8 \mathrm{ml} / \mathrm{kg}$ tahmin edilen vücut ağırlığ 1 ), orta PEEP (6-8 cmH2O) ve rekruitment manevralarını kullanan profilaktik akciğer koruyucu mekanik ventilasyonun, karın cerrahisi geçiren hastalarda fonksiyonel veya fizyolojik ve klinik postoperatif sonuç ile ilişkili olduğunun güçlü kanıtlarını sunmaktadır (4). Düșük tidal volüm ventilasyonu, yeterli PEEP ve tekrarlanan rekruitment manevralar1, özellikle büyük karın cerrahisi geçiren yüksek riskli hastalarda postoperatif pulmoner komplikasyonları azaltabilir (21).

$\mathrm{Bu}$ konuda yapılmış çalışma sayısı az olduğundan ileriki çalışmalar mekanik ventilatör başlangıcında akciğer hasarı olmayan hastalar için optimal ventilatör yönetim stratejilerinin değerlendirilmesini gerektirir.

\section{Kaynaklar}

1.Serpa Neto A, Cardoso SO, Manetta JA, Pereira VG, Esposito DC, Pasqualucci Mde O et al. Association between use of lung-protective ventilation with lower tidal volumes and clinical outcomes among patients without acute respiratory distress syndrome: a meta-analysis. JAMA 2012;308:1651-9.

2.Serpa Neto A, Schultz MJ, Slutsky AS. Current concepts of protective ventilation during general anaesthesia. Swiss Med Wkly. 2015;145:w14211

3.Hess DR, Kondili D, Burns E, Bittner EA, Schmidt UH. A 5 - year observational study of lung -protective ventilation in the operating room: A single-center experience. Journal of Critical Care 2013; 28: 533.e9-15

4.Futier E, Jaber S. Lung-protective ventilation in abdominal surgery. Curr Opin Crit Care 2014; 20: 426-30

5.Tao T, Bo L, Chen F, Xie Q, Zou Y, Hu B, et al. Effect of protective ventilation on postoperative pulmonary complications in patients undergoing general anaesthesia: a meta-analysis of randomised controlled trials. BMJ Open 2014; 4: e005208. doi:10.1136/ bmjopen-2014-005208

6.Ventilation with lower tidal volumes as campared with traditional tidal volumes for acute lung injury and the acute respiratory distress syndrome. The Acute Respiratory Distress Syndrome Network. N Engl J Med 2000; 342: 1301-8.

7.Güldner A, Kiss T, Serpa Neto A, Hemmes SN, Canet J, Spieth P, et al. Intraoperative Protective Mechanical Ventilation for Prevention of Postoperative Pulmonary Complications A Comprehensive Review of the Role of Tidal Volume, Positive End-expiratory Pressure, and Lung Recruitment Maneuvers. Anesthesiology 2015; 123: 692- 713

8.Richard JC, Maggiore SM, Jonson B, Mancebo J, Lemaire F, Brochard L. Influence of tidal volume on alveolar recruitment. Respective role of PEEP and a recruitment maneuver. Am J Respir Crit Care Med 2001; 163: 1609-13.

9.Brower RG, Lanken PN, Macintyre N, Matthay MA, Morris A, Ancukiewicz M, et al. Higher versus lower positive end-expiratory pressures in patients with the acute respiratory distress syndrome. N Engl J Med 2004; 351: 327-36.

10.Park SJ, Kim BG, Oh AH, Han SH, Han HS, Ryu JH. Effects of intraoperative protective lung ventilation on postoperative pulmonary complications in patients with laparoscopic surgery: prospective, randomized and controlled trial. Surg Endosc 2016 DOI 10.1007/s00464- 016-4797-x

11.Schultz MJ, Haitsma JJ, Slutsky AS, Gajic O. What tidal volumes should be used in patients without acute lung injury? Anesthesiology 2007; 106: 1226-31

12.Hong CM, Xu DZ, Lu Q, Cheng Y, Pisarenko V, 
Doucet D, et al. Low Tidal Volume and High Positive End-Expiratory Pressure Mechanical Ventilation Results in Increased Inflammation and Ventilator-Associated Lung Injury in Normal Lungs. Anesth Analg 2010; 110: 1652-60

13.Crotti S, Mascheroni D, Caironi P, Pelosi P, Ronzoni G, Mondino M, et al. Recruitment and derecruitment during acute respiratory failure: A clinical study. Am J Respir Crit Care Med 2001; 164: $131-40$.

14.Gattinoni L, Tognoni G, Pesenti A, Taccone P, Mascheroni D, Labarta V, et al. Effect of prone positioning on the survival of patients with acute respiratory failure. N Engl J Med 2001; 345: 56873.

15.Licker M, Diaper J, Ellenberger C. Perioperative protective ventilatory strategies in patients without acute lung injuries. Anesthesiology 2008; 108: 3356

16.Fernández-Pérez ER, Keegan MT, Brown DR, Hubmayr RD, Gajic O. Intraoperative tidal volume as a risk factor for respiratory failure after pneumonectomy. Anesthesiology 2006; 105: 14-8 17. Michelet P, D'Journo XB, Roch A, Doddoli C, Marin V, Papazian L, et al. Protective ventilation influences systemic inflammation after esophagectomy: a randomized controlled study. Anesthesiology 2006;105:911-9

18. Whalen FX, Gajic O, Thompson GB, Kendrick ML, Que FL, Williams BA, et al. The effects of the alveolar recruitment maneuver and positive endexpiratory pressure on arterial oxygenation during laparoscopic bariatric surgery. Anesth Analg 2006; 102: 298-305

19.Chalhoub V, Yazigi A, Sleilaty G, Haddad F, Noun R, Madi-Jebara S, et al. Effect of vital capacity maneuvres on arterial oxygenation in morbidly obese patients undergoing open bariatric surgery. EJA 2007; 24: 283-8

20. Yang D, Grant MC, Stone A, Wu CL, Wick EC. A Meta- analysis of intraoperative ventilation strategies to prevent pulmonary complications. Is low tidal volüme alone sufficient to protect healthy lungs? Ann Surg 2016; 263: 881-7

21.Park SH. Perioperative lung-protective ventilation strategy reduces postoperative pulmonary complications in patients undergoing thoracic and major abdominal surgery. Korean $\mathbf{J}$ Anesthesiol 2016; 69(1): 3-7. 